\title{
Orange-fleshed sweet potato (Ipomoea batatas) extract attenuates lipopolysaccharide-induced inflammation in RAW264.7 cells via inactivation of MAPKs and IKB signalling
}

\author{
Yada Saokosol ${ }^{1}$, Kemika Praengam² ${ }^{2}$ Monruedee Sukprasansap ${ }^{2} \&$ Siriporn \\ Tuntipopipat ${ }^{2^{*}}$ \\ ${ }^{1}$ Graduate student in Master of Science Program in Nutrition, Faculty of Medicine \\ Ramathibodi Hospital and Institute of Nutrition, Mahidol University, Thailand; \\ ${ }^{2}$ Institute of Nutrition, Mahidol University, Salaya, Nakhonpathom 73170, Thailand
}

\begin{abstract}
Introduction: Orange-fleshed sweet potato (OFSP) is an excellent source of $\beta$-carotene. Due to its health benefits, $\beta$-carotene-rich plants are receiving attention. This study aimed to assess the inhibitory effect of the ethanol extract of steamed OFSP on lipopolysaccharide (LPS)-induced inflammation in murine macrophage cell line (RAW 264.7 cells). Methods: $\beta$-carotene, total phenolics and total flavonoids of OFSP were measured by high performance liquid chromatography (HPLC), the FolinCiocalteu assay and the aluminum chloride colorimetry, respectively. RAW264.7 cell monolayers were pre-treated with $0.5-2.0 \mathrm{mg} / \mathrm{mL}$ ethanol extract from steamed OFSP prior to co-incubation with or without LPS for $24 \mathrm{~h}$. Culture media and cell lysate were collected to measure nitric oxide, interleukin-6 (IL-6), IL-1 $\beta$, tumour necrosis factor- $\alpha$, inducible nitric oxide synthase, cyclooxygenase-2, mitogenactivated protein kinases (MAPKs) and inhibitory kappa B (IкB), respectively. Results: The ethanol extract from steamed OFSP significantly suppressed LPSinduced production of such pro-inflammatory mediators by the inactivation of MAPKs and IкB signalling pathway. The ethanol extract from steamed OFSP contained $226 \mu \mathrm{g} / \mathrm{g}$ DW (dry weight) of $\beta$-carotene, $2.13 \mathrm{mg}$ gallic acid equivalent/g DW of total polyphenolics and $0.24 \mathrm{mg}$ quercetin equivalents/g DW of total flavonoids. Conclusion: These results indicated that bioactive compounds in steamed OFSP have anti-inflammatory potential.
\end{abstract}

Keywords: Orange-fleshed sweet potato, $\beta$-carotene, anti-inflammation, RAW264.7 cells, lipopolysaccharide

\section{INTRODUCTION}

Chronic inflammation has an association with the pathogenesis of obesity, metabolic syndrome and type 2 diabetes mellitus (Esser et al., 2014). During an inflammatory response, various transcription factors including nuclear factor-kappa B (NF-кB) are activated resulting in up-regulated expression of pro-inflammatory mediators (Liu et al., 2017). The over-expression of proinflammatory mediators during chronic

\footnotetext{
*Corresponding author: Siriporn Tuntipopipat, Ph.D.

Institute of Nutrition, Mahidol University, Salaya, Nakhonpathom, Thailand 73170

Tel: +66(0)-2800-2380; Fax: +66(0)-2441-9344; E-mail: siriporn.tun@mahidol.ac.th doi: https://doi.org/10.31246/mjn-2019-0011
} 
inflammation has been hypothesised to be an initiating or aggravating factor for development of some chronic diseases (Aggarwal \& Shishodia, 2004). The macrophage is an innate immune cell that plays an important role during inflammatory responses against noxious stimuli, including lipopolysaccharide (LPS). When macrophages are exposed to LPS, NF- $\kappa B$ and mitogen-activated protein kinases (MAPKs), including p-38, extracellular signal-regulated kinases (ERK1/2) and c-Jun N-terminal kinases (JNK) are activated, resulting in upregulation of various pro-inflammatory mediators including tumor necrosis factor- $\alpha$ (TNF- $\alpha$ ), interleukin- $1 \beta$ (IL- $1 \beta)$, interleukin-6 (IL-6), inducible nitric oxide synthase (iNOS) and cyclooxygenase-2 (COX-2) (Guha \& Mackman, 2001).

Various dietary phytochemicals including carotenoids, phenolic acids and flavonoids in colourful dietary plants have demonstrated multiple benefits including antioxidant, anti-cancer and anti-inflammatory activities (Aggarwal et al., 2009; Pan, Lai \& Ho, 2010). The sweet potato (Ipomoea batatas) with various coloured tuberous roots is an important staple food in Sub-Saharan Africa, Asia and the Pacific Islands. In particular, the orange-fleshed sweet potato (OFSP) is a good source of several nutrients, $\beta$-carotene, phenolic acids and flavonoids (Park et al., 2016). Being a rich source of $\beta$-carotene, previous studies have investigated its potential to improve vitamin A status in poor communities (Gurmu, Hussein \& Laing, 2014; Jamil et al., 2012). Recently, the impact of pasteurisation and sterilisation on its $\beta$-carotene content and bioaccessibility were evaluated in an OFSP-based baby puree (Dhuique-Mayer et al., 2018). Currently, the health benefits of $\beta$-carotene, such as its antioxidant and anti-inflammatory activities are gaining interest. In addition, the effect of thermal processing on carotenoid stability, total phenolics and antioxidant capacity of OFSP cultivars have been evaluated (Donado-Pestana et al., 2012). However, the anti-inflammatory activity of OFSP has never been investigated. This present study aims to assess anti-inflammatory activity of extract from OFSP in LPSstimulated murine macrophage cell line (RAW264.7 cells).

\section{MATERIALS AND METHODS}

\section{Chemicals and reagents}

The chemicals that were used were analytical and high performance liquid chromatography (HPLC) grade. Enzymelinked immunosorbent assay (ELISA) kits were purchased from BioLegend (San Diego, CA, USA). Antibodies against iNOS, COX-2, inhibitory kappa B (ІкB) and MAPKs were purchased from Cell Signalling Technology (Danvers, MA, USA). Anti-IL-1 $\beta$ was purchased from Peprotech (USA). Carotenoid standards, anti- $\beta$-actin-horseradish peroxidase (HRP), secondary antibody, Dulbecco's Modified Eagle's Medium (DMEM), LPS (E. coli O11:B4), 4-(2-hydroxyethyl)-1piperazineethanesulfonic acid (HEPES) were purchased from Sigma. Fetal bovine serum (FBS) was obtained from Merck (Darmstadt, Germany). Penicillinstreptomycin solution was purchased from Caisson labs (Smithfield, UT, USA). Trypsin-Ethylenediaminetetraacetic acid (EDTA) was purchased from Gibco (Grand Island, NY, USA).

\section{Preparation of steamed OFSP}

OFSP tubers were bought from three major distributors $(10 \mathrm{~kg}$ from each distributor) at a wholesale market at Pathum Thani province, Thailand. Each distributor, in turn, had bought the OFSP from three different growing areas (Nakhon Ratchasima, Lopburi and Suphanburi province). The tubers were washed with tap water and peeled 
prior to washing again with tap water. Approximately $1 \mathrm{~kg}$ of peeled OFSP from each distributor was steamed in a steaming basket over boiling water for $45 \mathrm{~min}$, cooled down at $25^{\circ} \mathrm{C}$ and blended with an electric kitchen blender, prior to lyophilization by freeze dryer (GEA Lyophil GmbH, Germany) to preserve stability of phytochemicals. The dried samples were homogenised by a kitchen electronic blender (Philips). An equal amount of dry sample from each distributor was pooled together and thoroughly mixed prior to being packed in aluminum foil under vacuum and stored at $-20^{\circ} \mathrm{C}$ until usage.

\section{Carotenoid analysis}

To $1 \mathrm{ml}$ deionised (DI) water, $0.02 \pm 0.001 \mathrm{~g}$ of dried sample was added. The resulting suspension was homogenised on ice by an ultrasonic processor (130 Watt, $20 \mathrm{kHz}$; Sonics \& Materials, Inc., Newton, USA) for three cycles of $30 \mathrm{sec}$ on/off pulsing (personal communication with Failla et al., 2018 at the Ohio State University). Nine $\mathrm{mL}$ of absolute ethanol (resulting in a $90 \%$ final concentration) was added to the suspended sample. Separately, to another suspension, $10 \mathrm{~mL}$ of mixed solvent [hexane:acetone:ethanol (2:1:1)] (Kubola \& Siriamornpun, 2011) was added. Both were thoroughly mixed for 2 min followed by sonication in an ultrasonic bath for $10 \mathrm{~min}$ (Daihan Scientific Co., Ltd., WUC-A02H, Korea) and centrifugation (Hettich, Rotina $38 \mathrm{R}$, Tuttlingen, Germany) at 4,140 g at $25^{\circ} \mathrm{C}$ for another $10 \mathrm{~min}$. The extraction procedures were repeated two times. The combined supernatants were evaporated untildrybyusing rotary evaporator(Buchi Rotavapor-Re-124, Switzerland) under vacuum at $38-40^{\circ} \mathrm{C}$. The dry film was reconstituted with $1.5 \mathrm{~mL}$ methyl-tertbutyl-ether (MtBE) and $500 \mu \mathrm{L}$ methanol before it was vigorously mixed and sonicated. The sample was then passed through $0.22 \mu \mathrm{m}$ polytetrafluoroethylene
(PTFE) membrane filter and diluted to an appropriate concentration with MtBE:methanol $(3: 1, \mathrm{v} / \mathrm{v})$ solution prior to analysis by HPLC. The carotenoid content was determined by the previously described method of Failla, Thakkar and Kim (2009) by using an HPLC system (Agilent 1100 series, Santa Clara, CA, USA) with photodiode array detector and separated in C30 reverse-phase column (YMC 150 mm x 4.6 mm ID, $5 \mu \mathrm{m}$, Japan) with a $\mathrm{C} 18$ cartridge guard column (4 $\mathrm{mm} \times 3 \mathrm{~mm}$ ID, Phenomenex, USA) at $25{ }^{\circ} \mathrm{C}$. Carotenoids were eluted at a flow rate of $0.6 \mathrm{~mL} / \mathrm{min}$ with $20 \mu \mathrm{L}$ injection volume. The mobile phases consisted of $98 \%$ methanol in ammonium acetate buffer (Solvent A) and MtBE (Solvent B) with the following solvent gradient profile: $80 \%$ A for $0-1 \mathrm{~min}, 60 \% \mathrm{~A}$ for $1-10 \mathrm{~min}, 40 \% \mathrm{~A}$ for $10-20 \mathrm{~min}, 25 \% \mathrm{~A}$ for $20-30 \mathrm{~min}$ and $80 \% \mathrm{~A}$ for $30-37 \mathrm{~min}$. The eluted carotenoids were identified by comparison of their retention time and absorption spectra at $450 \mathrm{~nm}$ with carotenoid standards and quantified by comparison of the peak area of sample with those of standard curves of lutein, zeaxanthin, $\beta$-cryptoxanthin, lycopene, $\alpha$-carotene and $\beta$-carotene.

\section{Determination of total polyphenol and flavonoid content}

To $2 \mathrm{~mL}$ deionised water was added $0.5 \pm 0.01 \mathrm{~g}$ of dried sample and the suspension homogenized on ice by an ultrasonic processor for three cycles of $30 \mathrm{sec}$ on/off pulsing. This was followed by the addition of $18 \mathrm{~mL}$ absolute ethanol and the mixture shaken at $25^{\circ} \mathrm{C}$ for $2 \mathrm{~h}$ before centrifugation at $1,400 \mathrm{~g}$ for $20 \mathrm{~min}$. The supernatant was collected to measure total polyphenols and flavonoids.

The total polyphenol content was determined by the Folin-Ciocalteu assay (Alhakmani, Kumar \& Khan, 2013). Twenty-five $\mu \mathrm{L}$ of extract or gallic acid (standards) or DI water (blank) were 
each transferred into 96-well microplate and mixed with $50 \mu \mathrm{L}$ of diluted FolinCiocalteu reagent $(1: 10)$ at $25^{\circ} \mathrm{C}$ for 5 min followed by addition of $200 \mu \mathrm{L}$ of $7.5 \%$ sodium carbonate $\left(\mathrm{Na}_{2} \mathrm{CO}_{3}\right)$ and incubated at $25^{\circ} \mathrm{C}$ for $2 \mathrm{~h}$ in the dark. The absorbance of the reaction mixture was measured at the wavelength of $760 \mathrm{~nm}$. The total phenol content was calculated by reading off the absorbance of sample from the gallic acid standard curve and expressed as mg gallic acid equivalent per gram of dry weight (mg GAE/g DW).

Total flavonoid content was measured by the colorimetric method of Prommuak, De-Eknamkul \& Shotipruk (2008). The $25 \mu \mathrm{L}$ of extract was mixed with $75 \mu \mathrm{L}$ of $90 \%$ ethanol, $5 \mu \mathrm{L}$ of $10 \%$ aluminum chloride, $5 \mu \mathrm{L}$ of $1 \mathrm{M}$ potassium acetate and $140 \mu \mathrm{L}$ of DI water. The mixture was incubated at $25^{\circ} \mathrm{C}$ for $30 \mathrm{~min}$ in the dark. Sample blank of extract and standard quercetin solutions were prepared in the same procedure by replacing aluminium chloride solution with DI water. The absorbance of the reaction mixture was measured at the wavelength of $415 \mathrm{~nm}$ and total flavonoid content was determined by comparing the absorbance of sample with those of quercetin standards and expressed as $\mathrm{mg}$ quercetin equivalents per gram dry weight (mg QE/g DW).

\section{Sample extraction for cell treatment}

Two sets of $0.50 \pm 0.02 \mathrm{~g}$ dried samples were suspended in $2 \mathrm{~mL}$ DI water and homogenised on ice by an ultrasonic processor for three cycles of $30 \mathrm{sec}$ on/off pulsing. Eighteen $\mathrm{mL}$ absolute ethanol was added in a suspended sample $190 \%$ ethanol) and $20 \mathrm{~mL}$ of mixed solvent was added to another suspended sample (less polar extract) and mixed for $2 \mathrm{~min}$ before sonication in an ultrasonic bath for $10 \mathrm{~min}$ and centrifugation at 4,140 $g$ for $10 \mathrm{~min}$ at $25^{\circ} \mathrm{C}$. The extraction procedures were repeated three times. The supernatants were evaporated until dry by using a rotary evaporator at $38-40^{\circ} \mathrm{C}$ and kept at $-20^{\circ} \mathrm{C}$ until use. Yields of $90 \%$ ethanol and mixed solvent extracts were $0.11 \pm 0.002 \mathrm{~g}$ and $0.05 \pm 0.002 \mathrm{~g}$, respectively. The dried extract was reconstituted with $0.2 \%$ dimethyl sulfoxide (DMSO) and further diluted to designated concentrations with serum/phenol free medium before passing through a sterile $0.2 \mu \mathrm{m}$ membrane filter for treatment with cell monolayers.

\section{Cell growth and activation}

Murine macrophage RAW264.7 cells were purchased from ATCC (Rockville, MD, USA). This cell line was established from a tumour induced by the Abelson murine leukemia virus derived from BALB/c mice. Stock RAW264.7 cells at passage number 6 were stored in liquid nitrogen. Cells with passage numbers of 10-20 were used in the experiments. The cells were grown in complete medium (DMEM supplemented with $10 \%$ FBS, 15 $\mathrm{mM}$ HEPES, $100 \mathrm{U} / \mathrm{mL}$ of penicillin and $100 \mu \mathrm{g} / \mathrm{mL}$ of streptomycin) at $37^{\circ} \mathrm{C}$ in humidified atmosphere of $5 \% \mathrm{CO}_{2} / 95 \%$ air. Cell monolayers were seeded for 24 $\mathrm{h}$ prior to incubation with or without non-toxic doses of extract or ferulic acid (FA), a well-known anti-inflammatory phenolic acid, in serum/phenol red free media for $1 \mathrm{~h}$ followed by co-culturing with or without $2 \mathrm{ng} / \mathrm{mL}$ LPS for another $24 \mathrm{~h}$.

\section{Cytotoxicity test}

The cytotoxicity of the OFSP extracts were assessed by sulforhodamine B (SRB) assay (Vichai \& Kirtikara, 2006), to select the non-toxic doses of the extract prior to conducting other experiments. Briefly, RAW264.7 cells were pre-treated with $0.5-2.0 \mathrm{mg} / \mathrm{mL}$ OFSP extracts from $90 \%$ ethanol or mixed solvent or $0.2 \%$ DMSO (vehicle control) or FA in serum/phenol red free media for $1 \mathrm{~h}$ prior to addition with or without $2 \mathrm{ng} / \mathrm{mL}$ LPS for another 
24 h. Cell monolayers were washed with cold phosphate-buffered saline (PBS) prior to fixing with $50 \%$ trichloroacetic acid and then incubated at $4^{\circ} \mathrm{C}$ for $2 \mathrm{~h}$. After excessive washing with DI water and air-drying, the cellular protein was stained with $7 \mathrm{mM}$ SRB in $1 \%$ acetic acid for $20 \mathrm{~min}$ before extensively rinsing with $1 \%$ acetic acid to remove excess SRB and air-drying. The protein stained with SRB was solubilized with $10 \mathrm{mM}$ Tris-hydro-methyl-aminomethane for 5 min on gyratory shaker. The absorbance was read at the wavelength of $500 \mathrm{~nm}$ and reference wavelength of $690 \mathrm{~nm}$ by a microplate reader. The absorbance was observed to be proportionate to the cell number. The absorbance of cells treated with LPS in the control vehicle was defined as $100 \%$ viability. The non-toxic doses of the extract were selected when the cells treated with extract and LPS had more than $90 \%$ cell viability relative to cells treated with LPS in the control vehicle.

\section{Measurement of nitric oxide (NO), TNF- $\alpha$ and IL-6}

After LPS stimulation, the culture media were collected to measure the nitrite concentration (a stable product of NO) by the Griess reagent, and, TNF- $\alpha$ and IL- 6 by ELISA kits (BioLegend, San Diego, CA, USA).

Briefly, $100 \mu \mathrm{L}$ of culture medium, standard sodium nitrite $\left(\mathrm{NaNO}_{2}\right)$ and DI water were each mixed with an equal volume of Griess reagent (1\% sulfanilamide in $5 \%$ phosphoric acid and $0.1 \% \quad N$-(1-Naphthyl) ethylenediamine dihydrochloride in DI water) and incubated for $10 \mathrm{~min}$ at $25^{\circ} \mathrm{C}$. The absorbance was measured at $520 \mathrm{~nm}$. $\mathrm{NO}$ level was estimated from a $\mathrm{NaNO}_{2}$ standard curve $(\mathrm{y}=0.0226 \mathrm{X}+0.0023$, $\left.\mathrm{R}^{2}=1\right)$.

Briefly, high-binding 96-well plates (NUNC, Roskilde, Denmark) were incubated overnight with capture antibody for mouse TNF- $\alpha$ and IL- 6 at $25^{\circ} \mathrm{C}$. After washing with $0.05 \%$ Tween-20 in PBS (PBST), the unbound sites were blocked with $1 \%$ bovine serum albumin (BSA) in PBS for $1 \mathrm{~h}$ at $25^{\circ} \mathrm{C}$. After washing with PBST, culture medium or recombinant mouse TNF- $\alpha$ or IL- 6 standards or DI water were added to each well and incubated for $2 \mathrm{~h}$ at $25^{\circ} \mathrm{C}$ prior to addition of biotinylated TNF- $\alpha$ or IL- 6 antibodies to each well. After 1 $h$ incubation and washing with PBST, the immune complex was detected with streptavidin HRP-tetramethylbenzidine detection system by incubating at $25^{\circ} \mathrm{C}$ for $30 \mathrm{~min}$. Reactions were terminated with sulfuric acid $\left(\mathrm{H}_{2} \mathrm{SO}_{4}\right)$ and the absorbance at $450 \mathrm{~nm}$ was measured by microtiter plate reader. Concentrations of TNF- $\alpha$ and IL- 6 in samples were calculated from their standard curves. The equations of TNF- $\alpha$ and IL- 6 standard curves were $\mathrm{y}=0.0015 \mathrm{X}+0.0481\left(\mathrm{R}^{2}=\right.$ $0.9978)$ and $y=0.0016 X+0.0092\left(R^{2}=\right.$ $0.9981)$, respectively.

\section{Western blot analysis}

After LPS activation, the treated cell monolayers were washed with cold PBS and treated with ice-cold lysis buffer [50 $\mathrm{mM}$ Tris-hydrochloride $\mathrm{pH}$ 7.4, $150 \mathrm{mM}$ sodium chloride $(\mathrm{NaCl}), 1 \mathrm{mM}$ EDTA, $1 \%$ Triton $\mathrm{X}-100,0.1 \%$ sodium dodecyl sulfate (SDS), 1\% phosphatase inhibitor cocktail (Bio Basic Inc., Ontario, Canada) and $0.5 \%$ protease inhibitor cocktail (Sigma)] at $4^{\circ} \mathrm{C}$ for $30 \mathrm{~min}$, on an orbital shaker. The supernatants of cell lysate were collected after centrifugation at $12,000 \mathrm{~g}$ at $4^{\circ} \mathrm{C}$ for $5 \mathrm{~min}$. The protein concentration was determined by bicinchoninic acid assay. Samples [20 $\mu \mathrm{g}, 40 \mu \mathrm{g}$ or $80 \mu \mathrm{g}$ protein/well for IL-1 $\beta$, iNOS, COX-2, IкB and MAPKs in loading buffer, respectively] were separated by $8 \%$ (for iNOS and COX-2), 10\% (for IkB and MAPKs protein) or $12 \%$ (for IL-1 $\beta$ ) of SDS-PAGE and transferred onto 0.45 $\mu \mathrm{m}$ nitrocellulose membranes (Whatman 
GmbH, Dassel, Germany). Other procedures were followed as previously described (Tuntipopipat et al., 2011).

\section{Statistical analysis}

Statistical Package for the Social Sciences (SPSS) version 19.0 (SPSS Inc., Chicago, IL) was used to analyze data. All data were presented as mean \pm standard deviation (SD) from at least two separate experiments conducted on separate days. The statistical significance was determined by one-way analysis of variance (ANOVA) with Tukey's HSD (honestly significant difference) test for multiple comparisons to identify mean differences among treatment groups. Statistical significance was set at $p<0.05$.

\section{RESULTS}

\section{Bioactive compounds in steamed OFSP extract}

The HPLC chromatograms identified that $\beta$-carotene was the predominant carotenoid in OFSP extracted with $90 \%$ ethanol and solvent mixture of hexane, acetone and ethanol (in supplementary material). The $\beta$-carotene content of ethanol extract from steamed OFSP was $226 \pm 11 \mu \mathrm{g} / \mathrm{g}$ DW, while that of mixed solvent extract was $283.8 \pm 8.6 \mu \mathrm{g} / \mathrm{g}$ DW. Total polyphenol and flavonoid content in the ethanol extract of OFSP were $2.13 \pm 0.05 \mathrm{mg}$ GAE/g DW and $0.24 \pm 0.01$ $\mathrm{mg} \mathrm{QE} / \mathrm{g} \mathrm{DW}$, respectively.

\section{Effect of $90 \%$ ethanol or mixed solvent extract from OFSP on cell viability}

The cells treated with $0.5-2.0 \mathrm{mg} / \mathrm{mL}$ of $90 \%$ ethanol or mixed solvent extracts or ferulic acid followed by LPS treatment had a cell viability of more than $90 \%$ as compared with those treated with LPS alone. These results indicated that 0.5$2.0 \mathrm{mg} / \mathrm{mL}$ of $90 \%$ ethanol or mixed solvent extracts or ferulic acid did not show a significant effect on cell viability.

\section{Comparison of $90 \%$ ethanol and} mixed solvent extracts from steamed OFSP on LPS-induced NO production RAW264.7 cell monolayers treated with ethanol extract from steamed OFSP at 0.5-2.0 $\mathrm{mg} / \mathrm{mL}$ significantly inhibited LPS-induced NO production in a dosedependent manner (Figure 1a) as compared to those treated with LPS alone $(p<0.05)$, whereas cells treated with the extract from mixed solvent did not show any suppressive effect (Figure 1b). Thus, only the ethanol extract was used to assess other anti-inflammatory activities in the present study.

\section{OFSP ethanol extract decreased NO production and iNOS expression}

RAW264.7 cells exposed to LPS significantly produced NO while vehicle treated cells or the cells treated with ethanol extract alone had no significant effect (Figure 2a). Compared to the LPS treatment group, cell monolayers treated with OFSP ethanol extracts or ferulic acid significantly decreased LPS-induced NO production $(p<0.05)$. $\mathrm{NO}$ is the product of enzyme iNOS. As expected, cells exposed to LPS upregulated iNOS protein expression (Figure 2c) and the extracts significantly suppressed LPS-induced iNOS protein expression in a dose dependent manner when compared to LPS-only treatment group $(p<0.05)$. Thus, the OFSP ethanol extract decreased NO secretion by inhibiting iNOS protein expression.

\section{OFSP ethanol extract inhibited TNF- $\alpha$, IL-6, IL-1 $\beta$ and COX-2 production}

Exposure of RAW264.7 cells to LPS significantly produced TNF- $\alpha$, IL- 6 and IL-1 $\beta$ whereas the control vehicle or cells treated with extract alone had no significant effect (Figure 2b, d and f). Cell monolayers treated with OFSP ethanol extracts or ferulic acid before co-incubation with LPS significantly 




(b)



Figure 1. Effect of ethanol and mixed solvent extracts on LPS-induced NO production. Cells were pre-treated with $0.5-2.0 \mathrm{mg} / \mathrm{mL}$ of (a) ethanol or (b) mixed solvent extract from steamed OFSP or $0.2 \%$ DMSO (D) or $25 \mu \mathrm{M}$ ferulic acid (FA) in serum/phenol red free media for $1 \mathrm{~h}$, followed by $2 \mathrm{ng} / \mathrm{mL}$ LPS for $24 \mathrm{~h}$. Ferulic acid was used as a control system. Nitrite in culture media was measured by Griess reagent. Data were expressed as mean $\pm S D(n=6)$. Different letters above the error bars indicated significant differences among treatment groups $(p<0.05)$

decreased TNF- $\alpha$, and IL- 6 production and IL-1 $\beta$ expression when compared to LPS-only treatment group ( $p<0.05)$.

COX-2 is an inducible proinflammatory enzyme produced by macrophages during the inflammatory process. As expected, RAW264.7 cells exposed to LPS significantly enhanced COX-2 expression, whereas cells pretreated with OFSP ethanol extracts or ferulic acid significantly inhibited LPSinduced COX-2 protein expression (Figure 2e) as compared to LPS-only treatment group $(p<0.05)$. These results indicated that bioactive compounds in the ethanol extract of OFSP exerted antiinflammatory activity by the suppression of LPS-induced pro-inflammatory mediator production.

\section{OFSP ethanol extract suppressed MAPKs phosphorylation}

Cell monolayers treated with LPS for $24 \mathrm{~h}$ markedly activated phosphorylation of ERK1/2, JNK and p38 (Figure 3a-c) without effecting their total ERK1/2, JNK and p38. Cell monolayers treated with the OFSP extract significantly inhibited phosphorylation of ERK1/2 and JNK in a dose-dependent manner (Figure 3a, b) whereas phosphorylation of p38 was significantly inhibited only at $1-2 \mathrm{mg} / \mathrm{mL}$ of the OFSP extract (Figure 3c) as compared to LPS-only treatment 
(a)



(b)



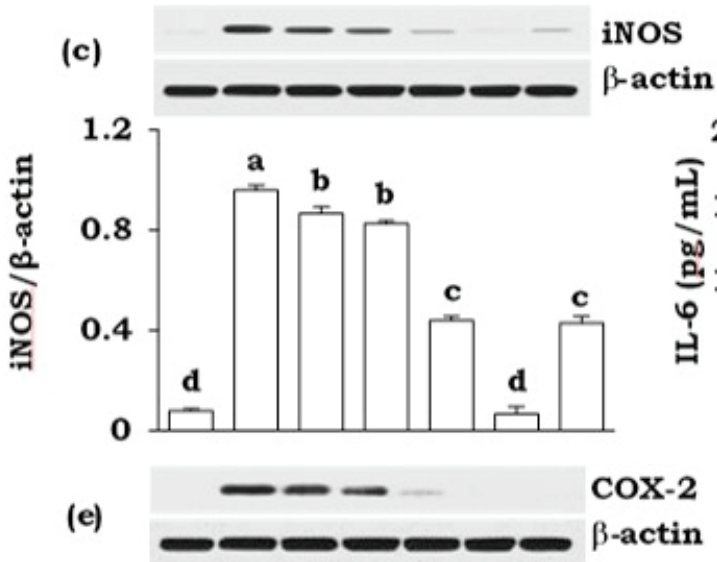

(d)



$\beta$-actin


Figure 2. Ethanol extract from steamed OFSP inhibited LPS-induced NO, TNF- $\alpha$, IL-6 production, iNOS, COX-2 and IL- $\beta$ expression. Cells were treated with $0.5-2.0 \mathrm{mg} / \mathrm{mL}$ ethanol extract or $0.2 \%$ DMSO (D) or $25 \mu \mathrm{M}$ ferulic acid (FA) in serum/phenol red free media for $1 \mathrm{~h}$, followed by $2 \mathrm{ng} / \mathrm{mL}$ LPS for $24 \mathrm{~h}$. Culture media were collected to measure (a) nitrite, (b) TNF- $\alpha$ and (d) IL-6 and cell lysates were collected to measure (c) iNOS/ $\beta$-actin, (e) COX- $2 / \beta$-actin and (f) IL- $1 \beta / \beta$-actin. Data were expressed as mean \pm SD $(n=6)$. Different letters above the error bars indicated significant differences among treatment groups $(p<0.05)$

group $(p<0.05)$. Ferulic acid treated cells also significantly suppressed phosphorylation of ERK1/2, JNK and p38 (Figure 3a-c). Thus, the steamed
OFSP ethanol extract inhibited proinflammatory mediator expression by blocking MAPKs phosphorylation. 



Figure 3. Ethanol extract from steamed OFSP inhibited LPS-activated MAPKs signalling. Cells were treated with $0.5-2.0 \mathrm{mg} / \mathrm{mL}$ ethanol extract or $0.2 \%$ DMSO (D) or $10 \mu \mathrm{M}$ ferulic acid (FA) in serum free media for $1 \mathrm{~h}$, followed by $2 \mathrm{ng} / \mathrm{mL}$ LPS for $24 \mathrm{~h}$ before collecting cell lysate to measure (a) phospho-ERK1/2 and total ERK1/2, (b) phospho-JNK and total JNK and (c) phospho-p38 and total p38. Data were expressed as mean $\pm S D(n=4)$. Different letters above the error bars indicated significant differences among treatment groups $(p<0.05)$

OFSP ethanol extract inhibited IKB phosphorylation and degradation

LPS activated RAW264.7 cells induced IкB phosphorylation and degradation
(Figure 4a, b). Pretreatment of cell monolayers with OFSP extract significantly inhibited LPS-activated IкB phosphorylation and degradation at 1-2 
(a)


(b)



Tota1 IкB $\beta$-actin



Figure 4. Ethanol extract from steamed OFSP inhibits LPS-activated IкB phosphorylation and degradation. Cells were pre-treated with $0.5-2.0 \mathrm{mg} / \mathrm{mL}$ ethanol extract or $0.2 \%$ DMSO (D) or $25 \mu \mathrm{M}$ ferulic acid (FA) in serum free media for $1 \mathrm{~h}$, followed by $2 \mathrm{ng} / \mathrm{mL}$ LPS for $24 \mathrm{~h}$ before


were expressed as mean $\pm S D(n=6)$. Different letters above the error bars indicated significant differences among treatment groups $(p<0.05)$

$\mathrm{mg} / \mathrm{mL}$ (Figure 4a, b) when compared with LPS-only treatment group $(p<0.05)$. These results indicated that steamed OFSP ethanol extract inhibited proinflammatory mediator production via suppression of IkB phosphorylation and degradation.

\section{DISCUSSION}

OFSP is a good source of macroand micro- nutrients and various phytochemicals (Wang, Nie \& Zhu,
2016). The present study found that OFSP extract contained $\beta$-carotene, polyphenols and flavonoids, which were consistent with data from previous studies (Failla et al., 2009; Tang, Cai \& $\mathrm{Xu}, 2015) . \beta$-carotene is the predominant carotenoid, which is consistent with a previous study (Failla et al., 2009). The ethanol extract contained 226 $\mu \mathrm{g} / \mathrm{g}$ DW of $\beta$-carotene while the mixed solvent extract contained $284 \mu \mathrm{g} / \mathrm{g}$ DW of $\beta$-carotene. A previous study in 
Taiwan (Liu, Lin \& Yang, 2009) reported the presence of $127-258 \mu \mathrm{g} / \mathrm{g}$ DW of $\beta$-carotene in mixed solvent extract of OFSP (Tainung 66 variety). However, the amount of mixed solvent extract in this study was slightly higher than that of the Taiwanese variety.

The ethanol extract from steamed OFSP contained $2.13 \mathrm{mg}$ GAE/g DW of total polyphenolic compounds. This figure was lower than the Chinese variety (5.19 GAE/g DW) (Tang et al., 2015) but was significantly higher than the Brazilian variety (1.05-1.56 mg GAE/g DW) (Donado-Pestana et al., 2012). Our study demonstrated that the total flavonoid content of steamed OFSP extract was $0.24 \mathrm{mg} \mathrm{QE} / \mathrm{g}$ DW which was slightly lower than the Taiwanese variety which had $0.33 \mathrm{mg}$ QE/g DW of total flavonoids (Huang, Chang \& Shao, 2006). The amount of $\beta$-carotene, polyphenol and flavonoid compounds in OFSP is dependent on many factors such as the variety, environmental conditions and agricultural management. In addition, the solvent used for extraction and the method used for the measurement of carotenoids by HPLC also influenced the measurable $\beta$-carotene content as reported in previous studies (Rautenbach et al., 2010). Therefore, it is difficult to compare our results for the amounts of bioactive compounds present in OFSP with those reported in other studies.

Besides $\quad \beta$-carotene, other compounds found in OFSP which have demonstrated anti-inflammatory activity include phenolic acids such as caffeic acid, $p$-hydroxybenzoic acid, vanillic acid, syringic acid, $p$-coumaric acid, FA, sinapic acid and flavonoids including quercetin, myricetin, kaempferol and luteolin (Ambriz-Pérez et al., 2016; Pan et al., 2010; Li, Hong \& Zheng, 2018). As OFSP contains various bioactive compounds such as phenolic acids, flavonoids (polar organic compounds) and carotenoids (non-polar organic compounds), the comparative effect of its extracts from ethanol (polar) and hexane:acetone:ethanol mixture (nonpolar) on LPS-induced NO production in RAW264.7 cells were investigated to select the potent solvent. The results revealed that the ethanol extract significantly inhibited NO production, whereas the mixed solvent extract did not show any suppressive effect (Figure $1 \mathrm{a}, \mathrm{b})$. Although mixed solvent extract contained a higher amount of $\beta$-carotene than the ethanol extract, its suppressive effect on LPS-induced NO production did not correlate with the $\beta$-carotene content. It implied that organic compounds in mixed solvent extract did not play major role in suppressive effect or mixed solvent extract may contain interfering compounds that neutralize such an inhibitory effect. Conversely, the polar organic compounds in the ethanol extract may play an important role in this inhibitory effect. Therefore, the ethanol extract was selected to further assess anti-inflammatory activity in the present study.

The ethanol extract also decreased NO secretion by inhibiting iNOS protein expression (Figure 2a, c). NO is a vital free radical that plays an important role in the progression of inflammation. It is synthesized by the oxidation of L-arginine to L-citrulline through the activity of NOS (Phaniendra, Jestadi \& Periyasamy, 2015). iNOS is up-regulated during inflammation leading to NO generation. LPS can stimulate macrophages to produce NO, which is mediated by activation of transcription factor "NFkB". Our results also demonstrated that OFSP ethanol extract inhibited the production of TNF- $\alpha$ and IL- 6 (Figure $2 \mathrm{~b}, \mathrm{~d})$ and suppressed IL- $1 \beta$ and COX2 expressions (Figure 2f, e). These proinflammatory cytokines and enzymes play crucial roles in activating the acute phase of immune response. They promote tissue damage in the pathogenesis of 
chronic inflammatory diseases and facilitate tumour progression and invasiveness. Additionally, prolonged overexpression of such pro-inflammatory mediators is mainly associated with the loss of apoptosis, uncontrolled cell proliferation, growth, metastasis, neovascularization and angiogenesis, leading to development of pathogenesis of various inflammatory diseases.

In addition, pre-treatment of RAW264.7 cells with OFSP extract inhibited LPS-induced pro-inflammatory protein expression by suppressing the phosphorylation of MAPKs including ERK, JNK and p38 (Figure 3a-c) and IкB activation (Figure 4a, b). These inflammatory effects of LPS are widely known as an important inducer for triggering the phosphorylation of MAPKs, resulting in NF-kB activation. MAPKs are serine/threonine protein kinases that mediate intracellular signalling related with the regulation of biological processes and cellular activities such as cellular stress, inflammatory responses, gene induction, cell proliferation, differentiation, survival, apoptosis and transformation (Kim \& Choi, 2010). Additionally, JNK activation has been associated with the regulation of cellular functions such as cell proliferation, survival and differentiation. JNK is activated by LPS, environmental stress, growth factors and inflammatory cytokines such as IL$1 \beta$ and TNF- $\alpha$. JNK plays an important role in the transcriptional regulation of many inflammatory mediators such as IL-2, iNOS and COX-2. Short-term JNK activation can promote cell survival, but prolonged JNK activation induces cellular apoptosis (Arndt et al., 2004). Furthermore, p38 activation has been implicated in the production and activation of inflammatory mediators for initiating leukocyte recruitment and activation. Also, p38 plays a key role in regulating the expression of various genes related to inflammation such as those encoding TNF- $\alpha$, IL- $1 \beta$, IL- 6 , IL8 , iNOS and COX-2 (Guha \& Mackman, 2001; Neuder et al., 2009).

The master transcription factor "NF$\kappa \mathrm{B} "$ is a dimer protein that is bound to IKB protein in cytoplasm during quiescent state. When macrophages are exposed to LPS, NF- $\mathrm{kB}$ is activated and IкB undergoes phosphorylation and degradation by the action of the IкB kinase (IKK) complex. NF- $\mathrm{kB}$ becomes free and is translocated into the nucleus, which then binds to responsive elements and induces many genes encoding inflammatory mediators including TNF- $\alpha$, IL-1 $\beta$, IL- 6, COX-2 and iNOS (Liu et al., 2017). The present results indicated that the suppressive effects of OFSP extract on pro-inflammatory mediator expression were mediated partly by inactivation of MAPKs (Figure 3a-c) and IкB (Figure 4a, b) signalling pathway. Therefore, the suppression of these signalling pathways may reveal the potent activity of our extract as an inhibitor of inflammatory mediators and cytokines.

The bioactive compounds present in the steamed OFSP extract may act synergistically to suppress inflammatory mediator production observed in the present study. According to a previous report, mouse peritoneal macrophages treated with phytonutrient mixture (lycopene or Lyc-O-Mato and carnosic acid, lutein, and/or $\beta$-carotene) revealed a synergistic inhibition of LPS-induced TNF- $\alpha, \quad N O$, prostaglandin $\mathrm{E}_{2} \quad\left(\mathrm{PGE}_{2}\right)$ and superoxide production derived from down-regulation of iNOS, COX-2 and nicotinamide adenine dinucleotide phosphate (NADPH) oxidase in both messenger RNA (mRNA) and protein expression. A combination of phytonutrients is known to exhibit an anti-inflammatory effect by the synergistic inhibition of LPS-induced internal superoxide production leading 
to a marked reduction in ERK and $\mathrm{NF}-\kappa \mathrm{B}$ activation, probably due to their antioxidant activities (Hadad \& Levy, 2012). This study identified and quantified the predominant carotenoid in the extract bioactive compound in OFSP, namely $\beta$-carotene. Supporting evidence indicated that synthetic $\beta$-carotene inhibited LPS-stimulated COX-2, iNOS and TNF- $\alpha$ gene expression in RAW264.7 cells (Kawata et al., 2018). $\beta$-carotene treatment inhibited the production and expression of various pro-inflammatory mediators in LPS stimulated RAW 264.7 cells by suppressing the phosphorylation and degradation of $\mathrm{I} \kappa \mathrm{B} / \mathrm{NF}-\kappa \mathrm{B}$ pathway (Li et al., 2018). However, phenolic acids including caffeic acid, $p$-hydroxybenzoic acid, vanillic acid, syringic acid, $p$-coumaric acid, FA and sinapic acid and flavonoids namely, quercetin, myricetin, kaempferol and luteolin were also found in OFSP (Park et al., 2016) which might exert anti-inflammatory activity along with $\beta$-carotene. Due to the potent antiinflammatory effect that were observed in the present study, OFSP may be an alternative promising functional food for preventing or reducing the risk of inflammatory diseases.

\section{CONCLUSION}

The present study indicated that the ethanol extract of steamed OFSP inhibited the production and expression of several pro-inflammatory mediators by suppressing the MAPKs and IкB activation on LPS-induced murine macrophage cell line. These findings clearly demonstrated that OFSP had antiinflammatory potential, and that regular consumption of OFSP may reduce risk of inflammatory diseases. However, this study is an in vitro experimental model. Further studies in animal models and humans are needed to confirm whether OFSP can be used as an alternative food supplement to prevent or alleviate severity of inflammatory diseases.

\section{Acknowledgement}

The authors would like to thank Ms. Christine Stanly at the Institute of Nutrition, Mahidol University for editing the manuscript.

\section{Authors' contributions}

YS, conducted the study, performed data analysis and interpretation, and prepared draft of the manuscript; KP, gave advice on the analytical methods and data analysis; MS, reviewed and edited the manuscript; ST, designed the study, gave advice on the analytical methods and data analysis, edited and overviewed the manuscript.

\section{Conflict of interest}

The authors declare that they have no conflicts of interest.

\section{References}

Aggarwal BB \& Shishodia S (2004). Suppression of the nuclear factor-kappaB activation pathway by spice-derived phytochemicals: reasoning for seasoning. Ann N Y Acad Sci 1030:434-441.

Aggarwal BB, Van Kuiken ME, Iyer LH, Harikumar KB \& Sung B (2009). Molecular targets of nutraceuticals derived from dietary spices: potential role in suppression of inflammation and tumorigenesis. Exp Biol Med (Maywood) 234:825-849.

Alhakmani F, Kumar S \& Khan SA (2013). Estimation of total phenolic content, in-vitro antioxidant and anti-inflammatory activity of flowers of Moringa oleifera. Asian Pac J Trop Biomed 3:623-627.

Ambriz-Pérez DL, Leyva-López N, Gutierrez-Grijalva EP \& Heredia JB (2016). Phenolic compounds: natural alternative in inflammation treatment. A Review. Cogent Food Agric 2:1131412.

Arndt PG, Suzuki N, Avdi NJ, Malcolm KC \& Worthen GS (2004). Lipopolysaccharide-induced c-Jun $\mathrm{NH}_{2}$-terminal kinase activation in human neutrophils: role of phosphatidylinositol 3-Kinase and Syk-mediated pathways. $J$ Biol Chem 279:10883-10891.

Dhuique-Mayer C, Servent A, Messan C, Achir N, Dornier M \& Mendoza Y (2018) Bioaccessibility of biofortified sweet potato carotenoids in baby food: impact of manufacturing process. Front Nutr 5:98.

Donado-Pestana CM, Mastrodi Salgado J, de Oliveira Rios A, dos Santos PR \& Jablonski A (2012). Stability of carotenoids, total phenolics and in vitro antioxidant capacity in the thermal processing of orange-fleshed sweet potato (Ipomoea batatas Lam.) cultivars grown in Brazil. Plant Foods Hum Nutr 67:262-270. 
Esser N, Legrand-Poels S, Piette J, Scheen AJ \& Paquot $N$ (2014). Inflammation as a link between obesity, metabolic syndrome and type 2 diabetes. Diabetes Res Clin Pract 105:141150.

Failla ML, Thakkar SK \& Kim JY (2009). In vitro bioaccessibility of beta-carotene in orange fleshed sweet potato (Ipomoea batatas, Lam.). $J$ Agric Food Chem 57:10922-10927.

Guha M \& Mackman N (2001). LPS induction of gene expression in human monocytes. Cell signal 13:85-94.

Gurmu F, Hussein S \& Laing M (2014). The potential of orange-fleshed sweet potato to prevent vitamin A deficiency in Africa. Int $J$ Vitam Nutr Res 84:65-78.

Hadad N \& Levy R (2012). The synergistic antiinflammatory effects of lycopene, lutein, $\beta$-carotene, and carnosic acid combinations via redox-based inhibition of NF-кB signalling. Free Radic Biol Med 53:1381-1391.

Huang YC, Chang YH \& Shao YY (2006). Effects of genotype and treatment on the antioxidant activity of sweet potato in Taiwan. Food Chem 98:529-538.

Jamil KM, Peerson JM, Brown KH, Haskell MJ, Keenan AH, Newman JW \& Jamil M (2012). Daily consumption of orange-fleshed sweet potato for 60 days increased plasma $\beta$-carotene concentration but did not increase total body vitamin A pool size in Bangladeshi women. $J$ Nutr 142:1896-1902.

Kawata A, Murakami Y, Suzuki S \& Fujisawa S (2018). Anti-inflammatory activity of betacarotene, lycopene and tri-n-butylborane, a scavenger of reactive oxygen species. In Vivo 32:255-264.

Kim EK \& Choi EJ (2010). Pathological roles of MAPK signalling pathways in human diseases. Biochim Biophys Acta 1802:396-405.

Kubola J \& Siriamornpun S (2011). Phytochemicals and antioxidant activity of different fruit fractions (peel, pulp, aril and seed) of Thai gac (Momordica cochinchinensis Spreng). Food Chem 127:1138-1145.

Li R, Hong $\mathrm{P}$ \& Zheng $\mathrm{X}$ (2018). $\beta$-carotene attenuates lipopolysaccharide-induced inflammation via inhibition of the $\mathrm{NF}-\kappa \mathrm{B}$, JAK2/STAT3 and JNK/p38 MAPK signalling pathways in macrophages. Anim Sci J 90:140148.

Liu SC, Lin JT \& Yang DJ (2009). Determination of cis- and trans- $\alpha$ - and $\beta$-carotenoids in Taiwanese sweet potatoes (Ipomoea batatas Lam.) harvested at various times. Food Chem 116:605-610.
Liu T, Zhang L, Joo D \& Sun SC (2017). NF-кB signalling in inflammation. Signal Transduct Target Ther 2:17023.

Neuder LE, Keener JM, Eckert RE, Trujillo JC \& Jones SL (2009). Role of p38 MAPK in LPS induced pro-inflammatory cytokine and chemokine gene expression in equine leukocytes. Vet Immunol Immunopathol 129:192-199.

Pan MH, Lai CS \& Ho CT (2010). Anti-inflammatory activity of natural dietary flavonoids. Food \& Funct 1:15-31.

Park SY, Lee SY, Yang JW, Lee JS, Oh SD, Oh S, Lee SM, Lim MH, Park SK, Jang JS, Cho HS \& Yeo Y (2016). Comparative analysis of phytochemicals and polar metabolites from colored sweet potato (Ipomoea batatas L.) tubers. Food Sci Biotechnol 25:283-291.

Phaniendra A, Jestadi DB \& Periyasamy L (2015). Free radicals: properties, sources, targets, and their implication in various diseases. Indian $J$ Clin Biochem 30:11-26.

Prommuak C, De-Eknamkul W \& Shotipruk A (2008). Extraction of flavonoids and carotenoids from Thai silk waste and antioxidant activity of extracts. Sep Purif Technol 62:444-448.

Rautenbach F, Faber M, Laurie S \& Laurie R (2010). Antioxidant capacity and antioxidant content in roots of 4 sweet potato varieties. $J$ Food Sci 75:C400-C405.

Tang Y, Cai W \& Xu B (2015). Profiles of phenolics, carotenoids and antioxidative capacities of thermal processed white, yellow, orange and purple sweet potatoes grown in Guilin, China. Food Sci Hum Wellness 4:123-132.

Tuntipopipat S, Muangnoi C, Chingsuwanrote P, Parengam M, Chantravisut P, Charoenkiatkul S \& Svasti S (2011). Anti-inflammatory activities of red curry paste extract on lipopolysaccharideactivated murine macrophage cell line. Nutrition 27:479-487.

Vichai V \& Kirtikara K (2006). Sulforhodamine B colorimetric assay for cytotoxicity screening. Nat Protoc 1:1112-1116.

Wang S, Nie S \& Zhu F (2016). Chemical constituents and health effects of sweet potato. Food Res Int 89(Part 1):90-116. 